\title{
Visões Perigosas: Para uma genealogia do cyberpunk
}

\author{
Adriana Amaral1 \\ Universidade Tuiuti do Paraná \\ adriamaral@yahoo.com
}

\begin{abstract}
Resumo: O presente artigo, resumo da tese de doutorado da autora, trata dos conceitos de cyberpunk enquanto um modo de ser estético da cibercultura $e$ o seu impacto na atualidade. Mapeamos alguns dos conceitos $e$ características do estilo cyberpunk, que é tanto um subgênero de fiççocientífica cuja tradição é herdada das visões distópicas do romantismo gótico (Amaral, 2004) quanto uma subcultura contemporânea (Thornton, 1996). Observa-se que sua estética permanece na comunicação e nas formas sociais através de um legado de atitude em relação à tecnologia (tais como nas tecnologias de mobilidade, nas novas mídias, nas artes eletrônicas em geral) e de reconfiguração corporal (biotecnologias, Inteligência Artificial, etc).
\end{abstract}

Palavras-chave: comunicação; cyberpunk; cibercultura; ficção-científica.

\begin{abstract}
This paper summarizes ideas presented on the author's PhD thesis and it's about cyberpunk concepts as an aesthetic way of being of cyberculture and its impact on contemporary trends. We've traced some of the aspects, characteristics and concepts of cyberpunk style, which is a science-fiction subgenre - with its tradition inherited from the distopic vision from gothic romanticism - as much as it is a contemporary subculture. We've analyzed that although the cyberpunk movement from the sci-fi literature is no longer here, its aesthetic has remained throughout communication and social forms composing a legacy of attitude towards technology (such as mobile devices of communication, new medias, electronic arts in general, etc) and also in the reconfiguration of the body (biotechnologies, artificial intelligence and so on).
\end{abstract}

Key Words: communication; cyberpunk; cyberculture; science-fiction.

Résumé: Cet article est une résumé des idées presentées dans la thèse de doctorat de l'auteur. Il est dedié aux concepts du cyberpunk comme une mode aesthétique d'être a la cyberculture et l'effet à l'âge contemporaine. On a pris certains concepts et caractéristiques du modéle cyberpunk, qui est un subgenre de la science-fiction dont la tradition est héritée des visions distopiques du romantisme gothique (Amaral, 2004), aussi bien qu'une subculture contemporaine (Thornton, 1996). On a analysée que l 'esthétique cyberpunk est present, malgré le fin du mouvement littéraire, à travers de la communication et des formes sociales, dans une attitude sur la technologie (technologies mobiles de communication, nouveaux médias, arts eletroniques

\footnotetext{
${ }^{1}$ Doutora em Comunicação Social pela PUCRS com Estágio de Doutorado (Bolsa Sanduíche CNPq) no Boston College, Estados Unidos. Professora e pesquisadora do Mestrado em Comunicação da UTP, Universidade Tuiuti do Paraná.
} 
in general, etc) et de la reconfiguration du corps (technologies biologiques, intelligence artificiel).

Mots-clés: communication; cyberpunk; cyberculture; science-fiction.

Resumen: Esto artículo, un resumen de la tesis de doctorado de la autora, trae los conceptos del cyberpunk como una forma de ser estético de la cibercultura y su impacto en la actualidad. Presentamos algunos de los conceptos y las características del estilo cyberpunk, que puede ser tanto un subgénero de ciencia- ficción cuya tradición es heredada de las visiones distópicas del romanticismo gótico (Amaral, 2004) cuanto una subcultura contemporánea (Thornton, 1996). Observamos que su estética permanece en la comunicación y en las formas sociales por medio de un legado de actitudes en relación a la tecnologia (las tecnologías de mobilidad, los nuevos medios, las artes electrónicas en general) y de la reconfiguración corporal (biotecnologias, inteligencia artificial, etc).

Pallabras-llave: comunicación; cyberpunk; cybercultura; ciencia-ficción.

\section{A estética cyberpunk - a volta do que não foi.}

Passaram-se mais de vinte anos entre o surgimento e a "morte" do cyberpunk enquanto tendência/movimento de ficção-científica. Apesar do tempo, essa estética característica da cibercultura permanece em objetos comunicacionais como games, música, flyers, moda, etc. Características como a fusão homemmáquina, o implante de memórias, a idéia de superação da carne pela mente, a dissolução entre real e simulação, o visual obscuro dos figurinos (a dupla couro + óculos escuros), a metrópole soturna e o estilo technoir ${ }^{2}$ continuam a permear o

${ }^{2} \mathrm{O}$ technoir é a mistura entre tecnologia e o estilo cinematográfico noir (dos anos 40), muito comumente visto em filmes como Blade Runner, Cidade das Sombras e Sin City, entre outros. 
imaginário pop, seja em letras de músicas, seja no campo cinematográfico, e mesmo em outras manifestações estéticas, científicas e tecnológicas³.

No domínio das ruas, assistimos ao desfile de tecnologias móveis como iPods e outros mp3 players, celulares, palmtops, redes wifis, muitas vezes funcionando como extensões de nossas memórias comunicacionais. Palavras do campo da informática como download, blogs, wi-fi são cada vez mais apropriadas pelas mídias e afetam o dia-a-dia das pessoas. A cultura do remix (Vianna, 2005) sampleia, recorta e cola os mais variados termos e atitudes para compor o mosaico cultural que vivemos. Partindo da premissa de que passamos de um momento de conexão para uma era de mobilidade (Lemos, 2005), visualizamos as tecnologias móveis (celulares, redes wifis etc) como "herdeiras" estéticas das propostas ficcionais dos cyberpunks.

Não vemos seres com implantes de chips nos cérebros, mas enviamos arquivos, mensagens, vídeos, fotos e músicas com a rapidez de um toque do polegar; vestimos tecidos inteligentes; colaboramos com o jornalismo open source, escrevemos blogs; reconfiguramos nossos corpos com cirurgias plásticas. Mesmo assim, os conceitos, as características e a própria influência do cyberpunk nesse contexto, parecem continuar encobertas por um manto negro de confusão eletrônica, que perpassam teorias que vão da crítica literária à sociologia. Esse artigo visa uma genealogia desses conceitos, destacando sua importância e influência na comunicação.

\subsection{Cyberpunk - o estado-da-arte no campo da comunicação e da cibercultura.}

A pesquisa dos conceitos de cyberpunk foi construída a partir da observação empírica de que eles estariam disseminados em ordens distintas: literária (o

Uma análise desse elemento encontra-se em AMARAL, Adriana. Explorando as sombras da distopia philipkdickiana - de como o cinema technoir legitimou o status cyberpunk de Philip K. Dick. 404notFound, Salvador, v.39, set. 2004. Disponível em:<http://www.facom.ufba.br/ciberpesquisa/404nOtFound/404_39.htm>

3 “As fronteiras difusas das pesquisas artísticas e cinetíficas com tecnologias fazem aparecer no contexto contemporâneo um território entrecruzado de complexas camadas genealógicas: a sensibilidade da arte, a objetividade da ciência, a complexidade das tecnologias. A criatividade de artistas e cientistas configura hoje uma grande comunidade, que ao lado de sociedades científicas, instituições e centros de pesquisa contemporâneos, está engajada na busca de explorar características próprias de nosso cotidiano tecnologizado" (Domingues, 2003, p. 11) 
movimento cyberpunk na FC nos anos 80), tecnológica e cultural (como elemento estético da cibercultura) e social (enquanto subcultura relacionada tanto a uma atitude política - hackers - quanto estética - a subcultura industrial). Vejamos então como se configuram essas duas vertentes: 1) como subgênero de ficção-científica e 2) como uma visão de mundo (Weltanschauung), através de seu impacto cultural que engloba uma subcultura de ordem da rebeldia juvenil.

Nos últimos vinte anos, o cyberpunk e suas imbricações na cultura contemporânea têm sido objeto de diversas pesquisas norte-americanas e européias, como em Bukatman (1993), McCaffery (1994),McCarron (1996), Featherstone e Burrows (1995), Roberts (2000), Dyens (2001) e Heuser (2003). Entretanto, percebe-se que há pouca sistematização dos conceitos e da importância do imaginário da FC nos estudos do campo da comunicação ${ }^{4}$ e da cibercultura.

Em relação ao Brasil, há pouquíssimas pesquisas sobre o assunto. Destacase o trabalho de Lemos com o texto "A cultura cyberpunk", de 1993, a contribuição da pesquisa do Núcleo de Cibercultura da FACOM/UFBA, chamada $A$ cultura cyberpunk no Brasil, e os capítulos V, VI e VII da Parte III do livro Cibercultura, publicado em 2002. Em uma consulta ao Banco de Teses e Dissertações da CAPES/CNPq ${ }^{5}$, até o presente momento, a primeira tese de doutorado específica sobre o tema é a da autora $^{6}$, fora isso, há duas dissertações de mestrado 7 . Há, portanto, uma lacuna no que diz respeito à especificidade da $\mathrm{FC}^{8}$ e do cyberpunk.

\footnotetext{
4 Entende-se a comunicação como as lacunas que preenchem a relação de forças entre os distintos fenômenos sociais aqui tratados.

5Disponível em http://www.capes.gov.br/capes/portal/conteudo/10/Banco Teses.htm. ${ }^{6}$ AMARAL, Adriana. Visões perigosas. Uma arque-genealogia do cyberpunk. Do romantismo gótico às subculturas. Comunicação e cibercultura em Philip K. Dick, tese de Doutorado, julho de 2005 no PPGCOM/PUCRS. Disponível em <http;//www.pucrs.br/famecos/pos/download/tese_adrianaamaral.pdf >. Esse artigo é um resumo e uma re-elaboração de algumas conclusões da tese.

7A primeira delas é de MENDONÇA, Carlos Magno Camargos. Subjetividade e sociabilidade na atitude cyberpunk. Belo Horizonte - MG. 01/07/1999. 1v. 110p. Mestrado. Universidade Federal de Minas Gerais - Comunicação Social. A segunda delas é de FERNANDES, Fábio. $A$ construção do imaginário cyber: William Gibson, criador da cibercultura. São Paulo - SP. 03/05/2004. Pontifícia Universidade Católica de São Paulo. A primeira trata das questões referentes à sociabilidade entre os grupos a partir do imaginário cyberpunk, utilizando a sociologia compreensiva de Michel Maffesoli,enquanto a segunda analisa a obra de William Gibson pelo viés da semiótica.

${ }^{8}$ Nesse sentido Muniz Sodré aparece como um dos pioneiros com a obra: A ficção no tempo: análise da narrativa de science-fiction publicada em 1973. Destacam-se também os trabalhos
} 
Outro ponto a ser ressaltado é a definição do papel e do campo da comunicação a partir do conceito de cyberpunk, como uma categoria cultural que permeia e é permeada pelo pensamento tecnológico e a mescla de elementos sintéticos e analógicos, máquinas e homens, cuja eficiência reprodutiva dos ambientes midiáticos pode apontar, como afirma Dyens (2001), uma independência dos artefatos tecnológicos em relação aos seres orgânicos,

Ambientes de mídia (mais especificamente, a Internet e as redes de telecomunicação, mas também coisas como as editoras, a indústria da música e do cinema) disponibilizam replicadores culturais a se liberarem da dependência dos seres orgânicos. (...) Além disso, a partir de uma perspectiva evolucionária, os ambientes de mídia são mais efetivos, mais rápidos e menos "duros" que os orgânicos. Quanto mais os ambientes de mídia se desenvolvem, mais os ambientes biológicos tendem a declinar (...) Nossa extinção (ou pelo menos as profundas mudanças às quais nossa vida será submetida) não será originada por um pedaço de estrela errante que colidirá com a terra, mas muito simplesmente das nossas telas de TV, religiões, websites, escritos, rádios, e assim por diante (DYENS, 2001, p. 18).

Para além da constante mediatização e aceleração das tecnologias de comunicação, o imaginário tecnológico ${ }^{9}$ aparece como um componente indissociável da potencialização material das mesmas, servindo como vetor de idéias acerca da cibercultura. É nesse domínio que se inserem os estudos de cibercultura dentro do campo da comunicação, estabelecendo questões de mediação $0^{10}$ entre o efeito das TICs (Tecnologias de Informação e Comunicação) na sociedade sem ignorar o efeito da própria sociedade nas TICs (HAKKEN, 1999, p. 41).

\section{Os conceitos e as influências do cyberpunk - cyber + punk.}

O termo cyberpunk foi primeiramente usado pelo escritor norte-americano Bruce Bethke em sua short-story ${ }^{11}$ homônima. Ela apareceu em uma estória

de TUCHERMAN, Ieda. Breve história do corpo e de seus monstros. 1. ed. Lisboa: Editora Vega, 1999. e a tese de doutorado de OLIVEIRA, Fatima C. Regis de. A ficção científica como narrativa da subjetividade homem-máquina. Tese de Doutorado, UFRJ, 2002.

9 Duas visões distintas acerca desse imaginário estão em SILVA(2000) e FELINTO (2005).

${ }^{10}$ Hakken (1999) enfatiza que uma das correntes etnográficas de pesquisa sobre o ciberespaço pretende aproximações entre ciberquestões de mediação, embora voltada para os Estudos Culturais e de Comunicação.

${ }^{11}$ A definição de Wolfe (1986, p. 118) para short-story é uma narrativa menor do que uma novela, que tenha entre 2.000 a 15.000 palavras. Segundo ele, a short-story possui 
publicada em novembro de 1984 na revista Amazing Stories, mas seu uso foi popularizado alguns meses mais tarde pelo jornalista do Washington Post, Gardner Dozois no seu artigo de 30 de dezembro de 1984, intitulado, "FC nos Anos 80" (SHINER apud DYENS, 2001, p. 105).

\subsection{O futuro de óculos escuros - o cyberpunk como movimento literário.}

Apesar da literatura e da cultura pop constituirem as forças e poderes que interagem e influenciam uma à outra; o movimento literário foi mais enfatizado no meio acadêmico; enquanto que a mídia chamou atenção para as práticas sociais e comunicacionais que surgiram com a nova cultura do computador, como é o caso dos hackers.

A parte "cyber" do nome desse movimento reconhece o seu compromisso em explorar as implicações de um mundo cibernético no qual a informação gerada por computador e manipulada torna-se uma nova fundação da realidade. A parte "punk" reconhece a sua atitude alienada e às vezes cínica para com a autoridade e o estabelecimento de todos os tipos (LANDON, 1997, p.160).

O surgimento da geração de escritores cyberpunks gerou debates acalorados através de editoriais de revistas, convenções de fãs, etc. Surgiram rótulos como The Movement (O Movimento), Mirrorshades Movement (Movimento dos Óculos Espelhados), Neuromancers (Neuromânticos), Newromancers (Novos românticos), New Wave of the 8os (Nova Onda dos Anos 80), tornando-se de uso comum do mercado (Shiner, 1992, p. 17) ${ }^{12}$.

Quando o New York Times utilizou o termo como sinônimo de hacker de forma pejorativa, ofendeu tanto a subcultura hacker como a da FC. O que vemos

influências realistas, mas também surrealistas. É um gênero literário que difere do conto e da novela, tipicamente na língua inglesa. No Brasil, não há correlato para o termo, uma vez que as características do conto são diferentes.

12 Vejamos algumas explicações para esses rótulos: The Movement: Para não utilizar o termo cyberpunk, que ele julgava um rótulo por demais comercial, o escritor John Shirley começou a referir-se a ele como "O movimento"; Mirrorshades movement; Essa etiqueta foi cunhada pelo escritor Lewis Shiner, e remete à citação do autor mainstream J.G. Ballard, "the future's so bright I have to wear shades" (O futuro é tão brilhante que é preciso usar óculos escuros) e também ao fato de que muitos personagens nas estórias cyberpunk usam óculos espelhados e alguns dos escritores como Lewis Shiner e Bruce Sterling também adotaram esse visual; Newromancers: Rótulo que remete ao livro de Gibson e que passou a ser utilizado após a publicação do artigo do teórico Istvan Csicsery-Ronay Jr chamado Cyberpunk and Neuromanticism de 1988. 
nesse caso é o que Thornton (1996) chama de autenticidade de uma subcultura ${ }^{13}$, cujo valor está diretamente ligado à legitimação dos seus participantes. Com a intensa popularização das temáticas e elementos do cyberpunk espalhados por diversas mídias, muitos autores quiseram "pegar carona" em seu apelo comercial, repetindo imagens e narrativas, tornando o estilo um clichê de si mesmo. Ele também se desdobrou em sub-subgêneros que se distanciaram bastante da proposta original.

TABELA 1

Sub-estilos de cyberpunk ${ }^{14}$ :

\begin{tabular}{|c|c|c|}
\hline $\begin{array}{l}\text { Sub- } \\
\text { subgênero }\end{array}$ & Temática & Estilo \\
\hline Biopunk $^{15}$ & $\begin{array}{l}\text { O centro do biopunk é a biologia, através } \\
\text { de biotécnicas de fusão corporal com } \\
\text { outros indivíduos, através da } \\
\text { manipulação genética dos cromossomos. }\end{array}$ & $\begin{array}{l}\text { O mais conhecido escritor desse campo é Paul } \\
\text { Di Filippo. Um exemplo cinematográfico seria } \\
\text { Robocop I. }\end{array}$ \\
\hline Steampunk & $\begin{array}{l}\text { Variante do cyberpunk em que a ação se } \\
\text { passa basicamente na Era Vitoriana, } \\
\text { criando um mundo paralelo em que a } \\
\text { sociedade vitoriana do final de século tem } \\
\text { acesso à tecnologia, contudo mantendo a } \\
\text { atitude punk. Mantêm os princípios } \\
\text { distópicos cyberpunks, mas combinando- } \\
\text { os com elementos vitorianos como as } \\
\text { máquinas de vapor (steam). O steampunk } \\
\text { também incorpora mais elementos } \\
\text { históricos e de fantasia (incorporando } \\
\text { personagens lendários), desdobrando-se } \\
\text { em "Clockpunk" (nas estórias que utilizam } \\
\text { maquinações de relógio), "sandalpunk" (as } \\
\text { estórias acontecem na Idade Antiga, por } \\
\text { ex, Roma), "bronzepunk" (estórias } \\
\text { centradas na Era do Bronze) e } \\
\text { "stonepunk" (estórias situadas na Era da } \\
\text { Pedra). }\end{array}$ & $\begin{array}{l}\text { Uma das principais obras de steampunk é a } \\
\text { novela The Difference Engine, escrita por } \\
\text { William Gibson e Bruce Sterling em 1992. A } \\
\text { estória aplica os princípios cyberpunks de } \\
\text { Gibson e Sterling a uma Era Vitoriana } \\
\text { alternativa onde o computador mecânico de } \\
\text { Charles Babbage foi efetivamente } \\
\text { construído.Outra obra importante são as duas } \\
\text { revistas em quadrinhos produzidas por Alan } \\
\text { Moore e Kevin O’ Neill, chamadas A league of } \\
\text { extraordinary gentlemen }{ }^{16} \text {. } \\
\text { Devido a popularidade do estilo entre as } \\
\text { pessoas envolvidas na cultura punk e gótica, } \\
\text { houve um movimento em direção a uma } \\
\text { subcultura steampunk, principalmente através } \\
\text { da moda, decoração e música, ou seja, de uma } \\
\text { estética. Os integrantes dessa subcultura, } \\
\text { muitas vezes são chamados de neovitorianos }{ }^{17} \text {. }\end{array}$ \\
\hline
\end{tabular}

13 Um outro fato importante e que difere a geração de escritores cyberpunk das anteriores é o aspecto mercadológico da FC, que foi difundido através de suas manifestações micromidiáticas (THORNTON, 1996, p. 137).como flyers, fanzines, listas, etc. ${ }_{14} \mathrm{~A}$ principal fonte para a elaboração dessa tabela foi a Wikipedia (www.wikipedia.org) ${ }_{15}$ McHale (1992, p. 257) traça um paralelo entre o biopunk e o gótico: "Não é difícil de ver que esses motivos revisam, atualizam e racionalizam os motivos clássicos de horror gótico de invasão corporal e disrupção. Esse é especificamente o caso com as variações bio-punks em torno do motivo de horror gótico clássico dos Filmes B: o tema do zumbi”.

${ }^{16}$ A Liga Extraordinária (The league of extraordinary gentlemen, Stephen Norrington, 2003, EUA/Ing.). 


\begin{tabular}{|l|l|l|} 
Splatterpunk & $\begin{array}{l}\text { Subgênero de horror (e não de FC) surgido } \\
\text { paralelamente ao cyberpunk, que mostra } \\
\text { cenas de violência apresentadas de forma } \\
\text { ainda mais gráfica e detalhista do que as } \\
\text { gerações anteriores }^{18} \text {. }\end{array}$ & $\begin{array}{l}\text { O escritor mais conhecido é Clive Barker, } \\
\text { embora aquele que seja considerado o mais } \\
\text { inovador seja David Schow. }\end{array}$ \\
\hline Mannerpunk & $\begin{array}{l}\text { Subgênero de fantasia, cunhado pelo } \\
\text { crítico Donald G. Keller em um artigo } \\
\text { chamado Tha manner of fantasy publicado } \\
\text { na Revista The New York Review of } \\
\text { Science Fiction em 1991. Tem sua } \\
\text { inspiração nas comédias de maneiras } \\
\text { (maneirismo de autores como Jane Austen } \\
\text { e Oscar Wilde) tanto como nos autores de } \\
\text { fantasia como J.R.R. Tolkien. Mistura } \\
\text { também aventura, intriga, magia e ficção } \\
\text { histórica. }\end{array}$ & $\begin{array}{l}\text { Entre os principais autores estão Pamela Dean } \\
\text { e Steve Brust. }\end{array}$ \\
\hline
\end{tabular}

FONTE - AMARAL (2005)

Na década de 90 começaram os anúncios da "morte" do cyberpunk enquanto movimento literário. As temáticas centrais são apropriadas e repetidas por outros autores. Gibson, Shirley e outros tentam se desvencilhar do termo. Em 1991, a novela Snow Crash de Neal Stephenson, é chamada de pós-cyberpunk. Em 1993, Paul Saffo publica o artigo Cyberpunk R.I.P. comparando o surgimento e desaparecimento do cyberpunk com a geração beatnik e o movimento hippie. O filme Johnny Mnemonic (Johnny Mnemonic, Robert Longo, EUA) baseado na short story de Gibson - que também assina o roteiro - é lançado em 1995. A película é um fracasso comercial, recebendo críticas negativas. Arthur e Marylouise Kroker, teóricos da cibercultura ${ }^{19}$,

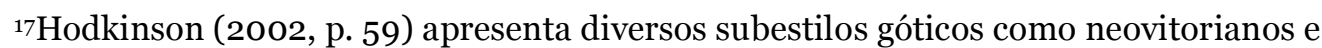
cybergóticos. Baddeley (2005) fala dos temas relacionados aos cybergóticos, "a atividade hacker e o ciberespaço - assuntos que têm se tornado cada vez mais dominantes na subcultura gótica, refletidos naqueles que começaram a se referir a si mesmos como 'cybergóticos'”. (Baddeley, 2005, p. 86)

${ }^{18}$ Mais informações sobre splatterpunk em Baddeley (2005): "Um novo movimento foi identificado pela primeira vez na Convenção Mundial de Fantasia de 1986 (...) David J. Schow "decidira que o horror gráfico que estave sendo produzido pelos escritores jovens, mórbidos e ávidos do gênero precisava de uma designação. O termo "cyberpunk" já havia sido cunhado para descrever a nova tendência fria e pessimista da ficção científica que iria introduzir uma era de realidades alternativas gerada por computador. Meio que de zombaria, Schow sugeriu que a nova geração selvagem do horror deveria ser definida como splatterpunk. O termo não vingou, mas (...) foi utilizado em determinadas ocasiões como um insulto a escritores que privilegiavam o sexo, a selvageria, os sobressaltos. (...) O splatterpunk trata de rebeldia, juventude e excitação, substituindo os clichês tradicionais do horror por referências da cultura trash atual na forma de programas de TV, fast food e rock n' roll” (Baddeley, 2005, p. 78-79). 19Editores da revista Ctheory (www.ctheory.net) 
comentam que o filme marca fenomenologicamente a morte do movimento, parecendo ingênuo e datado. Em 1999, Lawrence Person publica o artigo Notes towards a post-cyberpunk manifesto, onde fala sobre a emergência de uma nova estética literária que enfatiza um maior engajamento (social, político e até ecológico) das personagens. Saem os implantes metálicos e entram as bio e nano-tecnologias. Há inclusão de uma tecnocracia, considerando a sociedade como uma tecnologia em vez de apenas analisar os efeitos das TICs na sociedade. Da nova geração, destacamse autores Cory Doctorow, Warren Ellis e Nancy Kress. Para Heuser (2003), não houve morte do cyberpunk, mas sim uma transformação. O 'pós'cyberpunk é uma mutação do mesmo, que se recombinou com outros elementos da FC.

\subsection{O piloto da realidade - o cyberpunk como indivíduo da cibercultura.}

Da noção literária, passamos para a noção sociológica de cyberpunk, que aponta para um mentor por trás das transformações tecnológicas em curso, um piloto da realidade. Timothy Leary ([1988] 1994), defendia o cyberpunk como uma atitude em relação ao mundo contemporâneo e à Sociedade da Informação. Um comportamento que explora a criatividade individual através do uso de todas as informações e dados disponíveis via tecnologia.

Cyberpunk é uma terminologia popular, que pode ser aceita num sentido tolerante de humor "high tech", uma granada-significado atirada contra as barricadas conservadoras da linguagem. $\mathrm{O}$ cyberpunk é o piloto que pensa clara e criativamente, usando aplicações quântico-eletrônicas e know-how cerebral, o novo, atualizado modelo de ponta do século 21(...) Cyberpunks são os inventores, escritores inovadores, artistas tecnofronteiriços, diretores de filmes de risco, compositores de mutação icônica, artistas expressionistas, livre-cientistas tecno-criativos, visionários dos computadores empreendedores inovadores do show-bizz, hackers elegantes, videomagos dos efeitos especiais, pilotos de testes neurológicos, exploradores de mídia²0 (LEARY, [1988] 1994, p. 253).

A visão de Leary é próxima a de Lemos (2002) que afirma que a contracultura e a sociedade de massa contribuiu para o aparecimento dos cyberpunks como precursores da cibercultura, através de uma atitude contestadora e,

\footnotetext{
${ }^{20}$ Essa tradução é de Augusto de Campos e foi publicada no artigo Do caos ao espaço liberal, no Caderno Mais! da Folha de São Paulo, de domingo, o9 de novembro de 2003.
} 
conseqüentemente de uma formação social através de tribos urbanas distintas como hackers, crackers, zippers, cypherpunks, ravers, etc. Cyberpunk, além das figuras de revistas em quadrinhos, RPGs, games, etc é uma postura em relação ao mundo, seja esta a atitude encontrada no comportamento dos hackers e no ideário do livrefluxo da informação, do ciberativismo, ciberfeminismo ${ }^{21}$, defesa dos direitos do ciberespaço, movimentos de software livre, open source, jornalismo colaborativo, entre outros.

\section{As características do estilo cyberpunk e a formação de uma subcultura.}

O estilo da subcultura cyberpunk comporta múltiplas características, muitas delas herdadas do romantismo gótico ${ }^{22}$. Vamos tratar brevemente de três elementos que consideramos centrais: o sublime tecnológico e o neogrotesco, o ciborgue e a cidade. Tais elementos foram reconfigurados esteticamente através das figuras dos hackers e dos rivetheads ${ }^{23}$ em suas respectivas subculturas (hacker e industrial 24).

\subsection{O sublime tecnológico e o neogrotesco.}

Em 1756, Burke formula o conceito de sublime como o efeito estético que inspira ao mesmo tempo o terror e a dor, provocando emoções e contrapondo-se à placidez da beleza. O sublime é o efeito condutor do gótico, “(...) aquilo que desafia a

\footnotetext{
${ }^{21}$ Sobre o assunto ver algumas autoras como Haraway (1991) e Braidotti (2004).

${ }^{22}$ Ver as relações entre o romantismo gótico e o cyberpunk em AMARAL, Adriana. Espectros da ficção científica. A herança sobrenatural do gótico no cyberpunk. Revista Verso e Reverso, São Leopoldo, v. 38, ago. 2004. Disponível em:

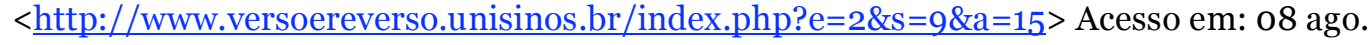
2004.

23Além da ligação entre os cyberpunks da ficção e os hackers das ruas, existem as subculturas juvenis de cunho artístico como a subcultura "industrial" (seus participantes são chamados de rivetheads ou cybergóticos). Ela tem como foco a mistura entre o sintético e o analógico, principalmente em relação à música ( o rock industrial, ou os gêneros eletrônicos como EBM, synthpop, technodark, etc). Uma análise mais aprofundada e comparativa dessas subculturas encontra-se em AMARAL, Adriana. Visões obscuras do underground - hackers e rivetheads, $o$ cyberpunk como subcultura híbrida. Revista 404notFound, Salvador, n.47, jul. 2005. Disponível em: $<$ http://www.facom.ufba.br/ciberpesquisa/404nOtFound/404_47.htm $>$. 24 DERY (1996) chama a música industrial ou rock industrial de "metal machine music' e afirma que ela faz parte do contexto estético do cyberpunk devido á sonoridade que mistura o sintético com o analógico e também devido ao visual das bandas, fetichista e ao mesmo tempo distópico que reflete a própria FC do período, sem contar a influência da música nos escritores cyberpunks. Já MONROE (1999) atenta para a hibridização e para os gênero e subgêneros que misturam o rock e o eletrônico.
} 
compreensão racional invocando uma mistura de prazer e terror no espectador" (BURKE apud DERY, 1999, p. 160). Por ser uma alegoria constante do romantismo, o sublime retorna, de várias formas, sobrevivendo às mais diferentes tendências e, conforme constata Tabbi (1995), persiste na época contemporânea como figura de poder emotivo, mediado agora pela ciência e pela tecnologia.

Uma atração e repulsão simultâneas à tecnologia, um prazer complexo derivado da dor da insuficiência representacional, produziu paradoxalmente um dos mais poderosos modos de escrita moderna na América - um sublime tecnológico que pode estar situado, conceitual e temporalmente, entre Educação de Henry Adams e o Manifesto Cyborg de Donna Haraway (TABBI, 1995, p.01).

Em vez de sublime tecnológico, Dery (1999) define a estética da cibercultura como Neo Grotesca. Através de exemplos retirados da cultura pop, ele conta a trajetória da estética neogrotesca, dos freakshows da época vitoriana aos videoclipes de NIN, David Bowie e Marylin Manson; do underground ao mainstream; dos relatos médicos expostos em museus ao cyberpunk, em um constante fluxo de forças. $\mathrm{O}$ corpo, a carne, o sangue, a matéria humana é a tônica dessa estética e, aparentemente se contrapõe às questões de descorporificação presentes nas temáticas cyberpunks. Apesar de tentar se livrar do "estorvo" no qual a carne teria se convertido, o corpo ainda é a fronteira final dos autores cyberpunks, que, em um primeiro momento de radicalismo tentaram abdicar dele, mas em seus escritos mais recentes - e na geração pós-cyberpunk - parecem re-corporificar as personagens.

Contrapondo a retórica cyberpunk de eterealização, com suas evocações rapsódicas de consciência corporificada superada pelo descarnado, existência "downloadeada" em memória de computador, o Novo Grotesco nos confronta com o fato inelutável de nossa mortalidade, lembrando-nos que (pelo menos por agora) as políticas do fim do século 20 aparecem em realidades físicas e não virtuais (DERY, 1999, p. 166).

\subsection{Humano, demasiado andróide - Andróide, demasiado humano.}

Outra figura recorrente é a do não-humano, seja ele inteligência ou vida artificial ou ciborgue e andróide. Para Gunkel (2001), o ciborgue 25 "constitui uma reconfiguração do sujeito que não apenas destrói o conceito de subjetividade humana, mas ameaça e promete

\footnotetext{
25A respeito de um rastreamento da figura do ciborgue, algumas referências básicas são Haraway ([1985] 1994), Gray (1995) e Hayles (1999).
} 
transformar a mesma questão do sujeito de estudo da comunicação humana" (GUNKEL, 2001, p. 174). Já Springer (1997), vê o conceito de ciborgue ligado às dicotomias como mente e corpo, humano e não-humano, analógico e digital. Nesse processo de subjetivação, o ciborgue aparece inserido no contexto dos estudos de comunicação, muito em função de uma influência tecnicista e mecanicista presente nas primeiras teorias da comunicação e na própria cibernética de primeira geração de Wiener (1948).

Os estudos de comunicação são uma disciplina que não apenas participa, mas que, inicialmente promove a hibridização ciborgue. (...) Em outras palavras, a comunicação, através de sua mais disciplinária gênese, é sempre parte de um programa ciborgue (...) o ciborgue já constitui o que subseqüentemente parece ameaçar. (...) Essa observação requere não apenas que se repense a tecnologia de comunicação, mas sim uma reorientação do sujeito da comunicação (GUNKEL, 2001, p. 183-184).

Além de um desdém em relação ao físico, uma fascinação com as formas pelas quais a carne é irrelevante comparada com a memória, o corpo ainda aparece como figura importante, seja através de suas modificações, implantes ou extensões. Ou, como relata Dery (1999) nas próprias deformações e aberrações do cyberpunk, o corpo ainda se faz presente.

Cyberpunk, TRON, Exterminador do Futuro 2, oferecem exemplos dessa preocupação invasiva a respeito da dissolução de fronteiras e do desafio eletrônico para a definição do sujeito. Essa preocupação não é menos endêmica ao campo da teoria cultural, onde escritores como Baudrillard, Haraway e Arthur e Marilouise Kroker têm recorrido à retórica da superimposição e à linguagem da ficçãocientífica para expressar a crise pós-moderna de um corpo que permanece central como um signo às operações do capitalismo avançado, enquanto se torna inteiramente supérfluo como objeto (BUKATMAN, 1993, p. 16).

\subsection{A cidade cyberpunk - o triunfo distópico.}

Nosso terceiro ponto é a figura da metrópole urbana ${ }^{26}$, apresentada como caótica, poluída e desorganizada em sua arquitetura gigantesca,e que aparece em diversas obras. Ela tem suas origens no romantismo gótico, no qual os autores decadentistas se inspiraram para buscar a atmosfera de pavor através das construções e edifícios, com o intuito de produzir um efeito no leitor. A cidade possui

\footnotetext{
${ }^{26}$ Para uma compreensão da cidade enquanto elemento distópico no cyberpunk ver AMARAL, Adriana. A metrópole e o triunfo distópico - a cidade como útero necrosado no cyberpunk. Revista Intexto, Porto Alegre, n.13, dez. 2005. Disponível em <http://www.intexto.ufrgs.br/>
} 
um papel fundamental servindo como uma identidade sombria, chuvosa e apavorante convertendo-se em distopia arquitetônica e metáfora para o ciberespaço; suas ruas como "veias sujas" e abertas para o crime e a desorganização. Um depositório de "outsiders" que participam do jogo entre as grandes corporações que dominam a tecnologia e os hackers que tentam subvertê-la. A cidade technoir apresentada pelo cyberpunk, converte-se em uma influência sendo absorvida e disseminada através da estética visivelmente perceptível em filmes como Blade Runner, animações como Akira, Ghost in the Shell.

Prungnaud (1997) descreve que, em um primeiro momento, a construção da novela gótica por excelência era a catedral. A catedral era uma metáfora para o corpo humano, pois os autores a percebem como um organismo vivo no qual há uma misteriosa harmonia. A imagem da catedral é resultado do projeto dos arquitetos da Idade Média que a conceberam como grandiosa e ao mesmo tempo como um lugar sagrado que representa a quintessência da feminilidade, a síntese da mãe, da esposa, da santa, da virgem, um lugar que não pode ser profanado.

De 1880 em diante, a catedral perde seu papel dentro da estrutura das estórias góticas para a aparição da metrópole urbana com sua desorganização, sua amplidão e ao mesmo tempo, claustrofobia. A cidade passa a ser então a metáfora do lugar gótico com sua estrutura labiríntica herdada dos fortes medievais. Essa segunda fase está bastante marcada historicamente pela industrialização, pela modernização das vilas que passam a ficar cada vez maiores e tornam-se cidades, pela dissolução dos vínculos sociais das pequenas comunidades. A paisagem caótica e o crescimento desenfreado da urbe têm em Paris e Londres colossais exemplos. O gigantismo da metrópole herda o aspecto selvagem que caracteriza o local da habitação gótica, fazendo com que ela desempenhe um papel central dentro da estrutura da narrativa. Esse gigantismo apresenta-se para Bassa e Freixas (1993) como um dos eixos temáticos primordiais da FC.

Se analisarmos a cidade como elemento integrante da vida, veremos que a metrópole e o desenvolvimento tecnológico caminham lado a lado. É por isso que, à medida que ela cresce e se desenvolve, de forma desordenada, sua importância aumenta exponencialmente dentro da FC, ocupando um lugar central no cyberpunk. A metrópole em sua feminilidade aparece no cyberpunk como uma mulher soturna, 
sombria, mal iluminada, ameaçadora e perigosa, em cujo útero foi gerado o espaço terminal (Bukatman, 1993) da existência humana e cujas ruas e construções abrigam seres híbridos, humanos e máquinas. O grande útero metropolitano encontra-se infectado pela tecnologia, necrosado e em vias de ser abandonado, tentando converter-se em dados, bytes, em informação pura a fim de transcender sua existência física em direção à alucinação consensual (Gibson, 1984) chamada ciberespaço.

Essa idéia da cidade obscura e perigosa que aparece nas imagens repetidas pelos filmes, nos videoclipes, games, etc, parece agora se transferir para aspectos mais lúdicos e disseminados através dos sistemas móveis de comunicação, como se em vez de termos invadido completamente o ciberespaço, o ciberespaço é que invadiu as ruas através das tecnologias wireless e wi-fi, liberando-nos da cultura presa ao computador pessoal em direção à liberdade de movimentação permitida pelas redes móveis, computadores vestíveis, etc.

\section{Considerações Finais - O legado da subcultura cyberpunk.}

A partir dos elementos apontados anteriormente conseguimos vislumbrar algumas facetas da chamada subcultura cyberpunk. Assim, podemos traçar algumas conexões entre a imagem literária/visual dos cyberpunks e a apropriação tecnológica das ruas, principalmente em seus aspectos estéticos e nas complexas relações entre moda/estilo, música e tecnologia, implícitas no "capital subcultural” (Thornton, 1996).

Eu creio que a moda está mais interessante, pois está começando a incorporar tecnologia usável - não exatamente implantes, mas na pele, casacos com fones de ouvido. O usuário médio de computador agora sabe menos sobre como manipular, dar forma ou adaptar o seu sistema de computador, o seu hardware do que há algumas décadas atrás, o foco agora está mais na usabilidade, mas também na moda e no estilo, especialmente quando você considera os produtos iPod e a estética Mac. Eu creio que as pessoas estão mais criativas em encontrar novos usos para as suas máquinas e bugigangas, algo que é mais notório na fusão entre telefones celulares, sistemas GPS, fotografia digital, agendas e mensagens de texto (HEUSER, 2005) ${ }^{27}$.

\footnotetext{
27Resposta concedida à autora em entrevista por e-mail.
} 
McCaffery (1994, p. 287/288) explicita as relações entre o punk e o cyberpunk, comentando que os últimos se apropriaram de "aspectos específicos da iconografia, estética e ênfases temáticas punks e as incorporaram em sua ficção". Essa atitude contida no cyberpunk divide com o próprio punk a questão do conhecimento adquirido nas ruas e o uso das tecnologias encontrado nos distintos grupos que habitam as metrópoles, aparecendo com clareza no discurso e nas narrativas cyberpunks, seja pela linguagem ou pelo estilo, e pela urbanidade (PORUSH, 1992, p. 254).

O punk e o cyberpunk "usam a tecnologia como uma arma contra ela mesma e tentam reduzir o controle de sua forma a partir dos efeitos da indústria da mídia e restabelecer um senso de ameaça, de intensidade" (McCAFFERY, 1994, p. 289). No sentido de uma abertura para uma possível conexão no que diz respeito à audiência que o movimento cyberpunk atingiu, Suvin (1991) explicitou.

Não é difícil de encontrar o leitor ideal do cyberpunk: hackers de computador, misturadores de mídia, técnicos de estações de rádio e TV, jovens profissionais móveis, free-lancers, que não se importam onde eles trabalham, seja em Tóquio, Londres, Düsseldorf ou Los Angeles - eles só querem ter suas máquinas, querem fazer parte de uma rede global (SUVIN, 1991, p. 257).

Suvin (1991) também comenta sobre o futuro de influência oriental (japonês em especial) na obra de Gibson e Sterling e de como essa "extrapolação simulada" feita por ele pode ser vista nas ruas. Por exemplo, o estilo gothic lolita, pode ser considerado como uma influência nipônica, tendo surgido a partir das meninas japonesas que se vestem como garotinhas (estudantes com micro-saias, meias seteoitavos, sapatos bonecas, maquiagem e cabelos presos em rabos de cavalo) personagens de mangá ou ídolos adolescentes japoneses, adoradas pelos otakus ${ }^{28}$.

Sterling (1990, p. 217) complementa sobre a inter-relação que há entre pessoas interessadas em tecnologia e o underground pop com os quais quem está de

\footnotetext{
${ }^{28}$ Nerds japoneses que se recusam a sair da adolescência colecionam informações das mais variadas formas, seja elas bonecos, ídolos, mangás, animes, etc. Uma boa inserção sociológica no tema dos otakus pode ser conferida no livro do jornalista francês BARRAL, Etienne.

Otaku. Os filhos do virtual. São Paulo: SENAC, 2000. Também confira o artigo de BRUNI, Paolo. Cyberpunks no Komikku. In: Revista 404notfound, Salvador, vol 1, n. 49, dez. 2005. Disponível $<$ http://www.facom.ufba.br/ciberpesquisa/404nOtFound/404_49.htm> Acesso em 15 dez. 2005.
} 
fora não está em contato. Ele cita o caso do fenômeno do cyberpunk no Japão: "Em Tóquio eles tratam o cyberpunk como cultura pop em vez de um fenômeno de gênero”. Imagens fortes são os mangás e animações (animes) que usam a temática cyberpunk como Ghost in the Shell 1 e $\mathbf{2}^{29}$, Geno Cyber, Cyberweapon, Cyber City Oedo, Akira, Aeon Flux, Akira, Robotech, Tetsuo e outros. Até Neuromancer ganhou sua versão quadrinizada.O uso da tecnologia pelas ruas, através das subculturas ${ }^{30}$ nos permite traçar algumas inferências a respeito da a configuração de um estilo cyberpunk, ou seja, uma espécie de hibridização, ou para utilizar um termo musical, um crossover entre as subculturas que lhe antecederam, e que lhe são contemporâneas. Observa-se o entrecruzamento de forças e de valores que geraram um fenômeno que ultrapassou as barreiras literárias e atingiu a visibilidade do social e que, ao mesmo tempo, equilibra-se entre o underground e o mainstream, entre as ruas e a imaginação dos autores de ficção-científica, entre a tecnologia e os movimentos sociais.

Mesmo passados mais de vinte anos do movimento literário, sua estética de fusão homem-máquina ainda aparece nos mais diversos produtos da cultura pop $e$ na cibercultura. No cinema, apenas para citar alguns exemplos, o estilo e/ou temáticas cyberpunks continuam sendo influentes, ora em filmes "alternativos" como Brilho Eterno de uma mente inquieta (Eternal Sunshine of a Spotless Mind, Michel Gondry, 2004) e Código 46 (Code 46, Michael Winterbottom, 2003) ou em blockbusters como Sin City (Frank Miller e Robert Rodrigues, 2005) e até mesmo

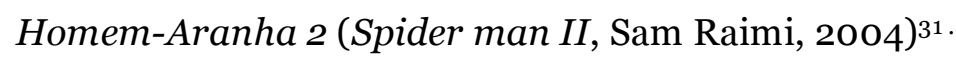

\footnotetext{
${ }^{29} \mathrm{Em}$ Ghost in the Shell 2 - Innocence, que estreou em 2004, são inúmeras as citações a autores como Donna Haraway (que é a personagem que cuida dos ciborgues), Descartes, Isaac Asimov e outros. A temática dos animais falsos nos remete diretamente à PKD, principalmente em Do androids?/Blade Runner. Disponível em <http://www.gofishpictures.com/GITS2/main.html>

30A importância do conceito de subcultura na concepção de cyberpunk encontra-sem AMARAL, Adriana. Uma breve introdução à subcultura cyberpunk. Estilo, transformações e hibridismo na cibercultura. In: Revista E-Compós, Brasília, n.03, ago. 2005. Disponível em $<$ http://www.assimcomunicacao.com.br/revista/documentos/agosto2005 adrianaamaral1.p df $>$ Acesso em 08 ago. 2005.

${ }^{31}$ Eternal Sunshine lida com a idéia de intervenção tecnológica nas memórias; Código 46 trata de um mundo futurista em que a bio-genética determina os relacionamentos possíveis; em Sin City, o visual neogótico está nos personagens e Homem Aranha 2 nos apresenta ao vilão Dr. Octopus que possui braços mecânicos implantados que acabam por dominar o cérebro do personagem.
} 
O legado do cyberpunk encontra-se mais próximo do que imaginamos e se destaca, basciamente, em quatro frentes. 1) Estética - no cinema technoir, na moda (computadores vestíveis, tecidos inteligentes, etc), na música eletrônica e suas subculturas (principalmente nos últimos tempos, no chamado electro-rock, mistura de analógico com digital), nos games, na ciberarte de artistas como Stelarc, entre outros; 2) Mobilidade: no uso intenso das tecnologias móveis (iPods, celulares), WiFi, Wireless, etc 3) Novas Mídias e movimentos sociais: jornalismo colaborativo, wikis, jornalismo open source, propriedade intelectual, blogs, redes e softwares sociais sociais, softwares livres, inclusão social, etc; 4) Biotecnologias: reconfigurações corporais, decodificação do DNA, Inteligência Artificial e processos cognitivos tecnológicos.

\section{Referências:}

AMARAL, Adriana. A metrópole e o triunfo distópico - a cidade como útero necrosado no cyberpunk. Revista Intexto, Porto Alegre, n.13, dez. 2005. Disponível em < http://www.intexto.ufrgs.br/>

AMARAL, Adriana. Uma breve introdução à subcultura cyberpunk. Estilo, transformações e hibridismo na cibercultura. In: Revista E-Compós, Brasília, n.03, ago. 2005. Disponível em <http://www.assimcomunicacao.com.br/revista/documentos/agosto2005 a drianaamaral1.pdf $>$ Acesso em 08 ago. 2005.

AMARAL, Adriana. Visões obscuras do underground - hackers e rivetheads, o cyberpunk como subcultura híbrida. Revista 404notFound, Salvador, n.47, jul. 2005. Disponível em:<http://www.facom.ufba.br/ciberpesquisa/404nOtFound/404 47.htm $>$.

AMARAL, Adriana. Explorando as sombras da distopia philipkdickiana - de como o cinema technoir legitimou o status cyberpunk de Philip K. Dick.

404notFound, Salvador, v.39, set. 2004. Disponível em:<http://www.facom.ufba.br/ciberpesquisa/404nOtFound/404 39.htm $>$

AMARAL, Adriana. Espectros da ficção científica. A herança sobrenatural do gótico no cyberpunk. Revista Verso e Reverso, São Leopoldo, v. 38, ago. 2004. Disponível em:

$<$ http://www.versoereverso.unisinos.br/index.php? $\mathrm{e}=2 \& \mathrm{~s}=9 \& \mathrm{a}=15>$ Acesso em: 08 ago. 2004. 
BADDELEY, Gavin. Goth Chic. Um guia para a cultura dark. Rio de Janeiro: Rocco, 2005.

BARRAL, Etienne. Otaku. Os filhos do virtual. São Paulo: SENAC, 2000.

BASSA, Joan, FREIXAS, Ramon. El cine de ciencia ficción. Una aproximación. Barcelona: Paidós.1 ${ }^{\text {a }}$ ed. 1993.

BUKATMAN, Scott. Terminal Identity. The virtual subject in post-modern science fiction. 4 ed. Durham: Duke Universtiy Press, 1993.

CAMPOS, Augusto de. Do caos ao espaço sideral. Folha de São Paulo. São Paulo, p.10-11, 09 nov. 2003. Caderno Mais!

CYBERPUNK INFORMATION DATABASE. Disponível em: $<$ http://project.cyberpunk.ru/idb> Acesso em mar. 2005.

DERY, Mark. Escape Velocity.NY: Grove Press, 1996.

DERY, Mark. The pyrotechnic insanitarium. American culture on the brink. NY: Grove Press, 1999.

DOMINGUES, Diana (org.). Arte e vida no século XXI. Tecnologia, ciência e criatividade. São Paulo: UNESP, 2003.

DYENS, Ollivier. Metal and flesh. The evolution of man: technology takes over. Cambridge: MIT Press, 2001.

FEATHERSTONE, Mike; BURROWS, Roger (ed.). Cyberspace Cyberbodies Cyberpunk. London: Sage, 1996.

FELINTO, Erick. A religião das máquinas. Ensaios sobre o imaginário da cibercultura. Porto Alegre: Sulina, 2005.

FERNANDES, Fábio. A construção do imaginário cyber: William Gibson, criador da cibercultura. São Paulo: PUCSP, 2004. Dissertação (Mestrado em Comunicação e Semiótica), Pontifícia Universidade Católica de São Paulo, 2004.

FREIRE FILHO, João. Das subculturas ás pós-subculturas juvenis; música, estilo e ativismo político. In: Revista Contemporânea, Salvador, vol. 03, n.01, junho de 2005. Disponível em:

<http://www.contemporanea.poscom.ufba.br/6\%20joaof\%20j05w.pdf> Acesso em 30 de jul. 2005.

GIBSON, William. Neuromancer. New York: Ace Books, 1984.

GRAY, Chris Hables et al. (ed.). The cyborg handbook. New York: Routledge, 1995 .

GUNKEL, David J. Hacking cyberspace. Boulder: Westview Press, 2001.

HAKKEN, David. Cyborgs @ cyberspace? New York: Routledge, 1999.

HARAWAY, Donna. Um manifesto para os ciborgs: ciência, tecnologia e feminismo socialista na década de 80. In: HOLLANDA, Heloisa Buarque de (org.). Tendências e impasses. $O$ feminismo como crítica da cultura. Rio de Janeiro: Rocco, 1994. 
HAYLES, N. Katherine. How we became posthuman: virtual bodies in cybernetics, literature and informatics. Chicago: The University of Chicago Press, 1999.

HEUSER, Sabine. Virtual geographies. Cyberpunk at the interesection of the postmodern and science fiction. Amsterdam: Rodopi, 2003.

HODKINSON, Paul. Goth: identity, style, and subculture. New York: Berg, 2002.

KROKER, Arthur e Marylouise. Johnny Mnemonic: the day cyberpunk died. CTheory, 14 jun.1995. Disponível em:

<http://www.ctheory.net/text file.asp?pick=150> Acesso em: 10 jan. 2005.

LANDON, Brooks. Science Fiction after 1900. From the steam man to the stars. NY: Twayne Publishers, 1997.

LEARY, Timothy. The cyberpunk: the individual as reality pilot.In: McCAFFERY, Larry. Storming the reality studio. A casebook of cyberpunk and postmodern fiction. London: Duke University Press, [1988]1994.

LEMOS, André. Cibercultura. Tecnologia e vida social na cultura contemporânea. Porto Alegre: Sulina, 2002.

LEMOS, _ _ Cibercultura e mobilidade. A era da conexão. Trabalho apresentado no NPo8 - Tecnologias da Informação e da Comunicação do INTERCOM, set. 2005.

LEVY, Steven. Hackers. Heroes of the computer revolution. Anchor Press: New York, 1984.

McCAFFERY, Larry. Introduction: the desert of the real. In: Storming the reality studio. A casebook of cyberpunk and postmodern fiction. London: Duke University Press, 1994.

McCARRON, Kevin. Corpses, Animals, Machines and Mannequins: The Body and Cyberpunk. In: FEATHERSTONE, Mike; BURROWS, Roger (ed.). Cyberspace Cyberbodies Cyberpunk. London: Sage, 1996.

McHALE, Brian. Constructing postmodernism. New York: Routledge, 1992.

MENDONÇA, Carlos Magno Camargos. Subjetividade e sociabilidade na atitude cyberpunk. Belo Horizonte: UFMG, 1999. Dissertação (Mestrado em Comunicação Social), Universidade Federal de Minas Gerais, 1999.

OLIVEIRA, Fatima C. Regis de. A ficção científica como narrativa da subjetividade homem-máquina. Tese de Doutorado, UFRJ, 2002.

PERSON, Lawrence. Notes towards a post-cyberpunk manifesto. Slashdot. o9 Out. 1999. Disponível em:

<http://slashdot.org/features/99/10/08/2123255.shtml> Acesso em: 28 jan. 2005.

PORUSH, David. Frothing the synaptic bath: what puts the punk in cyberpunk? In: SLUSSER, George, SHIPPEY, Tom. Fiction 2ooo. Cyberpunk and the future of narrative. Athens: 
PRUNGNAUD, Joëlle. Gothique et décadance. Recherches sur la continuité d'un mythe et d'un genre au XIXe siècle en Grande-Bretagne et en France. Paris: Honoré-champion. 1997.

SUVIN, Darko. An interview with Darko Suvin. Science Fiction and History, Cyberpunk, Russia. Science Fiction Studies, Greencastle, v. 18, n. 54, p.253-61, jul. 1991.

ROBERTS, Adam. Science Fiction. London: Routledge, 2000.

SAFFO, Paul. Cyberpunk R.I.P. Revista Wired. Set-Out. 1993. Disponível em: <http://www.wired.com/wired/archive/1.04/1.4 cyberpunk pr.html> Acesso em: 28 jan. 2005.

SILVA, Juremir Machado da. As tecnologias do imaginário. Porto Alegre: Sulina, 2003.

SODRÉ, Muniz. A ficção no tempo: análise da narrativa de science fiction. Petrópolis: Vozes, 1973.

SPINRAD, Norman. Science Fiction in the real world. Carbondale: Southern University Press, 1990.

SPRINGER, Claudia. The electronic eros. Dallas: Texas University Press, 1997.

STERLING, Bruce. Preface from Mirrorshades. In: McCAFFERY, Larry. Storming the reality studio. A casebook of cyberpunk and postmodern fiction. London: Duke University Press, [1988] 1994.

TABBI, Joseph. Postmodern sublime. Technology and american writing from Mailer to cyberpunk. London: Cornell University Press, 1995

THORNTON, Sarah. Club cultures. Music, media and subcultural capital. Connecticut: Wesleyan University Press, 1996.

TUCHERMAN, Ieda. Breve história do corpo e de seus monstros. 1. ed. Lisboa: Editora Vega, 1999.

VIANNA, Hermano, LEMOS, Ronaldo. A tradição remixada. In: Folha de São Paulo, 04/09/2005. Disponível em $<$ http://www.gilbertogil.com.br/sec_news.php?page=2\&id=96\&language_id $=1>$

WARK, McKenzie. A hacker manifesto. Cambridge: Harvard, 2004.

WOLFE, Gary K. Critical terms for science fiction and fantasy. A glossary and guide to scholarship. NY: Greenwood Press, 1986. 